\title{
Symptomatic gastric sarcoidosis with multiple antral ulcers
}



Fig. 1 Gastroscopic finding. Multiple ulcers of the antrum, irregular-shaped or serpiginous aphthoid.

Sarcoidosis is a systemic granulomatous disease of unknown etiology that is characterized by the formation of noncaseating granulomas. Although it affects many systems, the disease has a predilection for the intrathoracic structures. Almost 90\% of sarcoidosis patients have granulomas in the lungs and/or hilar nodes [1]. Gastrointestinal tract involvement in sarcoidosis is rare. Gastric sarcoidosis, particularly involving the antrum, affects approximately $10 \%$ of patients with systemic disease [2]. Gastrointestinal sarcoidosis commonly occurs subclinically, with clinical manifestations present in only $0.1 \%$ $0.9 \%$ of patients with the disease. This is a rare case report of an individual with symptomatic gastric sarcoidosis.

A 66-year-old woman followed up for eye and lung sarcoidosis suffered nausea, epigastralgia, and weight loss. She underwent bronchoscopy and transbronchial biopsy which showed a noncaseating epithelial cell granuloma, and bronchoalveolar lavage which demonstrated a lymphocytic pattern suggestive of sarcoidosis. On upper endoscopy, several superficial ulcers were evident in the antral region (๑ Fig. 1).

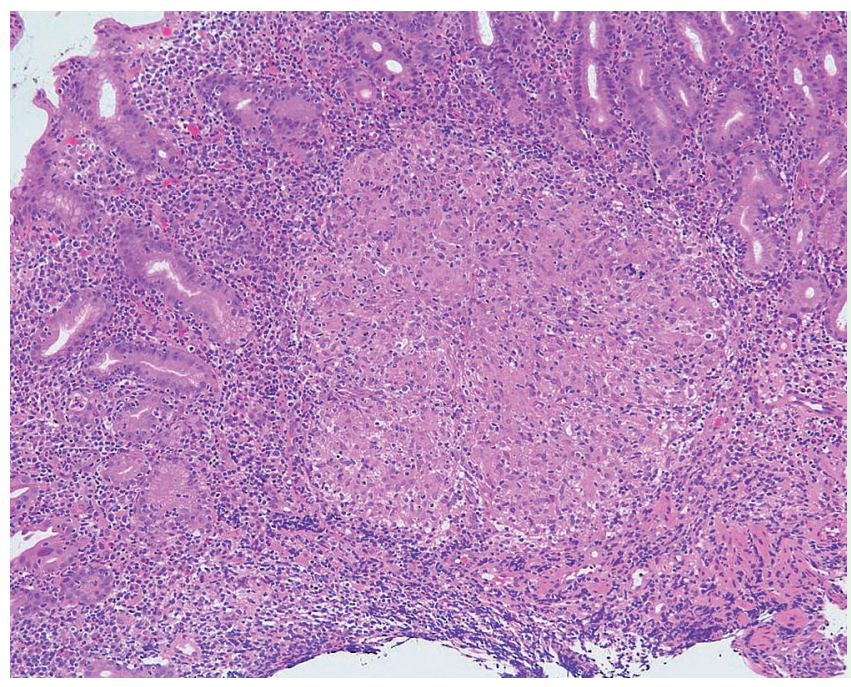

Fig. 2 Histopathologic finding. A noncaseating epithelioid-cell granuloma including giant cells, surrounded by the infiltration of lymphocytes and proliferation of fibroblastic cells (H\&E stain, $\times 100$ ).

Mucosal biopsies from the antral ulcers showed noncaseating granulomas (๑ Fig. 2).

The specimen was negative for Helicobacter pylori. Tests using special stains for fungi (methenamine silver), acid-fast bacilli (Ziehl-Neelsen), and treponema (Warthin-Starry) gave negative results. This case illustrates the importance of endoscopy examinations for patients with sarcoidosis, particularly those with intractable primary lesions, in order to detect gastrointestinal sarcoidosis.

Endoscopy_UCTN_Code_CCL_1AB_2AD_3AC

T. Akiyama ${ }^{1}$, H. Endo ${ }^{1}$, M. Inamori ${ }^{1}$, H. lida ${ }^{1}$, K. Hosono ${ }^{1}$, K. Fujita ${ }^{1}$, M. Yoneda $^{1}$, H. Takahashi ${ }^{1}$, A. Goto ${ }^{1}$, Y. Abe ${ }^{1}$, H. Kirikoshi ${ }^{1}$, N. Kobayashi ${ }^{1}$, K. Kubota ${ }^{1}$,

S. Saito ${ }^{1}$, K. Nagahama ${ }^{2}$, Y. Inayama²,

\section{A. Nakajima}

1 Gastroenterology Division, Yokohama City University School of Medicine, Japan

2 Department of Pathology, Yokohama City University Hospital, Japan

\section{References}

1 James DG, Nevilli E, Siltzbach LE. A worldwide review of sarcoidosis. Ann N Y Acad Sci 1976; 278: 321 - 328

2 Fireman Z, Sternberg A, Yarchovsky Y et al. Multiple antral ulcers in gastric sarcoid. J Clin Gastroenterol 1997; 24: 97 - 99

\section{Bibliography}

DOI 10.1055/s-0029-1214690

Endoscopy 2009; 41: E159

(c) Georg Thieme Verlag KG Stuttgart · New York . ISSN 0013-726X

\section{Corresponding author}

\section{Inamori, MD}

Gastroenterology Division,

Yokohama City University School of Medicine

3-9 Fukuura

Kanazawa-ku

Yokohama

236-0004

Japan

Tel.: +81-45-787-2640

Fax: +81-45-784-3546

inamorim@med.yokohama-cu.ac.jp 